\title{
A (DELICADA) NOÇÃO DE INTENCIONALIDADE NA ATENÇÃO CONJUNTA
}

\author{
The (delicate) notion of intentionality in joint attention
}

\author{
José Moacir Soares da COSTA FILHO \\ Instituto Federal da Paraíba \\ jmscostafilho@gmail.com \\ https://orcid.org/0000-0003-1755-2525
}

RESUMO: Compreender a presença da intencionalidade nas ações de crianças em aquisição da linguagem tem sido apontado por pesquisadores a exemplo de Melo (2015), Costa Filho (2016), Ávila-Nóbrega (2017), dentre outros, como um desafio para a discussão deste conceito dentro dos estudos sobre atenção conjunta. Desse modo, o objetivo deste artigo é discutir a noção de intencionalidade comunicativa presente em contextos de atenção conjunta. Primeiramente, destacamos as contribuições teóricas de Bruner $(1975 ; 1983)$ e Tomasello (2003) a respeito da teoria da atenção conjunta, entendendo-a com um processo interativo que se consolida durante o primeiro ano de vida das crianças. Em seguida, discutimos a noção de intencionalidade apresentada especialmente por Tomasello e Carpenter (2007). Considerando que essa noção é delicada do ponto de vista teórico e analítico, propomos, a partir do conceito de Beaugrande e Dressler (1981), uma perspectiva para a compreensão da intencionalidade em cenas de atenção conjunta. Após isso, trazemos dois exemplos de interações de atenção conjunta coletados em diferentes contextos interativos com crianças para discutir a noção de intencionalidade por meio da perspectiva proposta. Percebemos, por fim, que a intencionalidade comunicativa dentro da atenção conjunta parece apontar para escolhas e ações realizadas pela criança para atingir um objetivo dentro da interação. PALAVRAS-CHAVE: Intencionalidade; Atenção conjunta; Interação.

ABSTRACT: Understanding the presence of intentionality in children's actions during language acquisition has been pointed by researchers such as Melo (2015), Costa Filho (2016), Ávila-Nóbrega (2017), among others, as a challenge to the discussion of this concept in studies about joint attention. Thus, the aim of this paper is to discuss the notion of communicative intentionality in contexts of joint attention. Firstly, we consider Bruner $(1975 ; 1983)$ and Tomasello's (2003) theoretical contributions about the theory of joint attention,

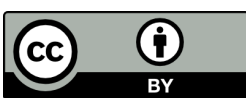


understanding it as an interactive process that is consolidated during children's first year of life. Secondly, we discuss the notion of intentionality mainly presented by Tomasello and Carpenter (2007). Considering that this notion is delicate when it comes both to theorical and analytical points of view, we propose a perspective to the comprehension of intentionality in joint attention scenes based on the concept presented by Beaugrande and Dressler (1981). After that, we show two examples of joint attention interactions collected in different interactive contexts with children to discuss the notion of intentionality through the proposed perspective. Lastly, we notice that the communicative intentionality seems to point to both choices and actions conducted by the child to achieve an objective during the interaction. KEYWORDS: Intentionality; Joint attention; Interaction.

\section{INTRODUÇÃO}

Dentro dos estudos em aquisição que contemplam a linguagem como um conjunto multimodal, composto tanto pelo aspecto verbal (fala) quanto pelos elementos não verbais (gestos, olhares, expressões faciais), a atenção conjunta se posiciona como uma teoria a partir da qual é possível observar de que forma as crianças se inserem na linguagem ao longo dos primeiros anos de vida.

Enquanto teoria, as primeiras considerações sobre a atenção conjunta surgem a partir dos trabalhos de Bruner $(1975 ; 1983)$, que situa a atenção conjunta como um dos processos não verbais que fazem parte da rotina da criança que ainda não domina a estrutura verbal da língua. Para o referido autor, o papel da atenção conjunta, assim como dos demais elementos não verbais, é o de garantir o lugar da criança dentro das interações sociais nas quais se insere.

Partindo das considerações de Bruner, Tomasello (1995; 2003) aprofunda as pesquisas sobre a atenção conjunta com crianças em interação social com os sujeitos que as cercam. Com base nos resultados de suas investigações, Tomasello (2003) argumenta que a atenção conjunta surge na rotina infantil por volta dos nove meses de vida, dentro de um período que chama de "revolução dos nove meses", e concomitantemente ao momento em que as crianças começam a compreender o outro como agente intencional.

A partir da compreensão do outro como agente intencional, ou seja, como um sujeito que realiza ações com um determinado objetivo, quase que de maneira intrínseca, a noção de intencionalidade está presente nas discussões sobre atenção conjunta. Essa noção se destaca, no entanto, não por ser importante para a compreensão da atenção conjunta enquanto um processo, mas sim por ser delicada do ponto de vista conceitual, 
já que quando a trazemos à baila, surgem questões como: é possível mensurar a intencionalidade do outro? Em se tratando de uma criança, de que maneira poderíamos verificar a intencionalidade dentro de situações em que ela interage com adultos?

A dificuldade de compreender a intencionalidade nas ações de crianças que ainda estão adquirindo a linguagem tem sido um ponto enfatizado por pesquisadores que discutem o processo de atenção conjunta. Melo (2015), por exemplo, debruçou-se sobre o conceito de intencionalidade por compreender que o próprio Tomasello (1995; 2003), mesmo trazendo o conceito de agente intencional durante suas contribuições teóricas para a atenção conjunta, não define claramente a noção de intencionalidade. Ávila-Nóbrega (2017) segue o pensamento de Melo (2015) e amplia a discussão apontando para o conceito de atencionalidade, por meio do qual, o autor sugere que a criança, durante as cenas de atenção conjunta, demonstra uma capacidade de atenção, mas não necessariamente carrega uma intenção (compreendida como propósito) durante as interações com seus parceiros interativos.

Especialmente em nossa Tese de Doutorado (COSTA FILHO, 2016), destacamos também a dificuldade de mensurar a intencionalidade em ações realizadas por crianças em cenas de atenção conjunta. Por não ser o objetivo principal da nossa pesquisa naquele momento, optamos por não ampliar a discussão, mas compreendemos que intencionalidade nas crianças em processo de atenção conjunta diz respeito muito mais a uma expectativa de engajamento com o outro, do que a uma busca por alcançar determinado objetivo.

Considerando a delicadeza da questão da intencionalidade e a partir das indagações que lançamos anteriormente, o objetivo do presente artigo é discutir a noção de intencionalidade comunicativa presente em contextos de atenção conjunta. Para tanto, iniciamos o artigo com a exposição de algumas discussões teóricas que norteiam a relação entre intencionalidade e atenção conjunta. Em seguida, buscamos respaldos teóricos acerca da intencionalidade em uma perspectiva de produção linguística, especialmente em trabalhos como o de Beaugrande e Dressler (1981). Por fim, analisamos dados de atenção conjunta, coletados com crianças em diferentes contextos interativos, que serão explicitados à medida que expusermos tais dados.

Destacamos já de início que o presente trabalho configura-se como proposta para a compreensão do conceito de intencionalidade em cenas de atenção conjunta com crianças, e, muito embora já tenhamos abordado o tema em outras pesquisas (COSTA FILHO, 2011; COSTA FILHO, 2016; COSTA FILHO \& CAVALCANTE, 2018; COSTA FILHO, 2017), a discussão que apresentamos neste artigo são iniciais e buscam contribuir 
com futuros estudos sobre atenção conjunta por meio de uma nova perspectiva para a análise da intencionalidade comunicativa.

A seguir, iniciamos a discussão teórica situando o conceito da intencionalidade dentro da atenção conjunta.

\section{A INTENCIONALIDADE NA ATENÇÃO CONJUNTA}

Conceber a atenção conjunta dentro da aquisição da linguagem, de modo geral, significa tomá-la como um processo interativo. É a partir dessa perspectiva processual, e com base na noção de andaimes (BRUNER, 1975; WOOD, BRUNER, ROSS, 1976), que trazemos a proposta apresentada na figura 1 que segue para explicar o processo que culmina na consolidação da atenção conjunta.

Figura 1: Andaime da atenção conjunta.

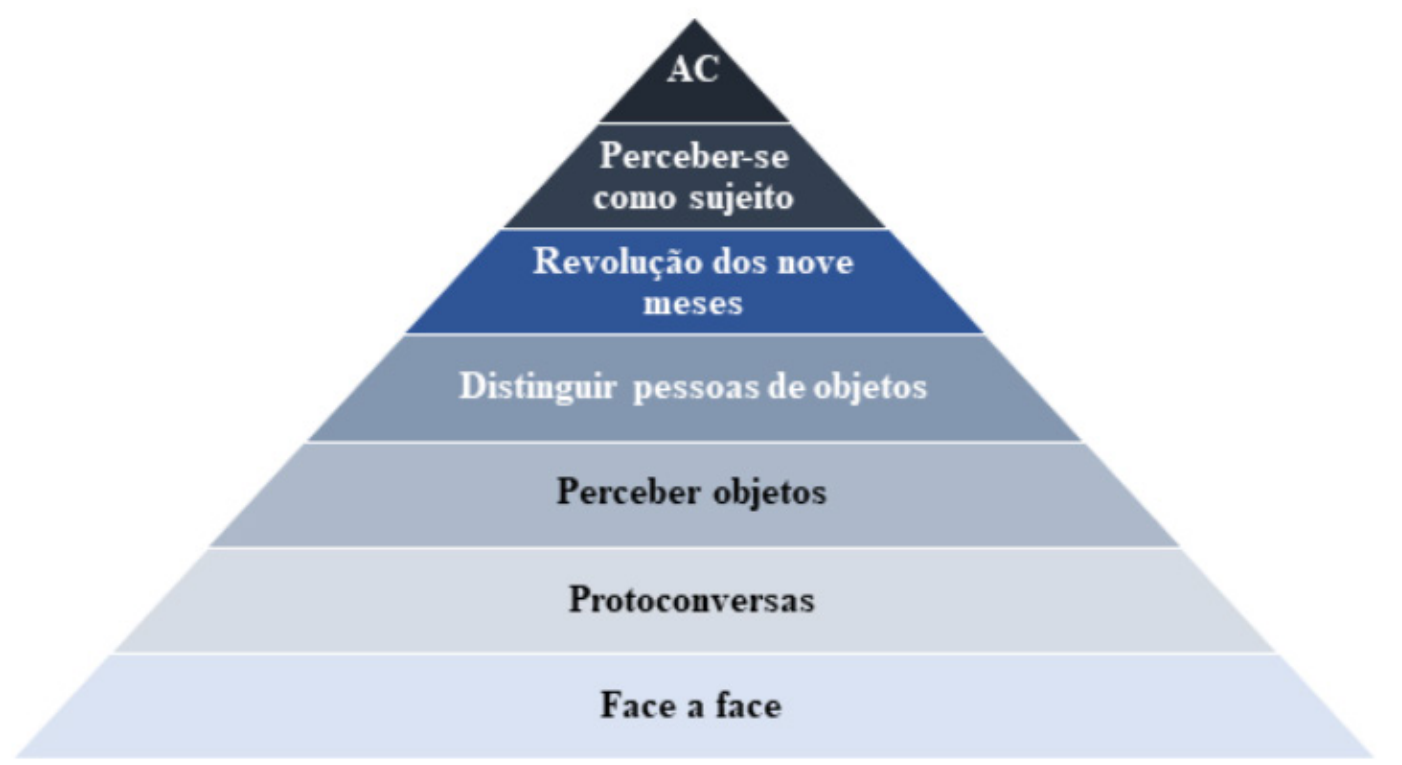

Fonte: Costa Filho (2016, p. 29).

Já durante as primeiras interações após o seu nascimento, a criança começa a desenvolver movimentos faciais que culminam no que Cavalcante (1994) define como interações em que adulto e criança se olham, podendo haver troca de sorrisos e expressões faciais, ou seja, o face a face. As protoconversas, por sua vez, vão além do face a face. Como destaca Tomasello (2003, p.81), elas são interações que envolvem, em um contexto de face a face, toques e vocalizações que permitem à criança "expressar e compartilhar Revista X, v. 16, n. 6, p. 1460-1475, 2021. 
emoções básicas". A partir dos quatro meses de vida, a criança demonstra perceber a existência de objetos, e, logo em seguida, começa a distinguir objetos de pessoas, um processo muito importante para a atenção conjunta já que é a partir dele que a criança começa a perceber que com pessoas ela interage em torno dos objetos, que serão o foco do formato de atenção conjunta.

Com uma rotina de interações face a face estabilizada e tendo compreendido objetos e outras pessoas, a criança aproxima-se de seu primeiro aniversário e começa a se engajar em interações de atenção conjunta. Regular, manter e reconhecer a atenção entre o parceiro na troca interativa e o objeto ao qual presta atenção juntamente com o outro requer da criança outra habilidade: a compreensão da intencionalidade e, consequentemente, do outro como um agente intencional. Essa é a perspectiva de Tomasello (2003) quando defende que, dentro do período denominado "revolução dos nove meses", por representar um momento na vida do bebê em que uma série de processos cognitivos se intensificam, a criança passa a reconhecer o seu interlocutor, e a si mesma, como agente intencional.

A intencionalidade na comunicação, ou comunicação intencional, ainda é um tema não muito discutido, como já destacava Bosa (2002), e que está situado nos fundamentos epistemológicos da atenção conjunta. Além disso, é um processo complexo que está diretamente associado à troca de informações, quer seja verbal ou não verbalmente (BOSA, 2002; MELO, 2015). Desse modo, as ações dos parceiros na interação podem ser interpretadas pelo outro como intencionais, ou seja, como ações que querem atingir um determinado objetivo. Por exemplo, se um bebê chora, a mãe possivelmente interpreta que ele está com fome, com sono ou com cólicas. Para cada uma das possíveis interpretações, há uma reação materna que pode confirmar que houve troca de informação entre bebê e mãe por meio do choro da criança.

Algumas características da comunicação intencional podem ser percebidas na atenção conjunta, e, neste ponto, concordamos com o posicionamento de Bosa (2002, p. 79) quando a autora enfatiza que "a comunicação intencional [...] envolve a coordenação entre gesto e olhar, em direção a um parceiro", pois as estratégias não verbais que a autora traz à discussão representam algumas das estratégias de que a criança, principalmente quando ainda não tem consolidada a linguagem verbal, lança mão para estabelecer e marcar seu lugar nas cenas de atenção conjunta. Isso reforça também o argumento de que na atenção conjunta está inserida a comunicação intencional, fazendo com que os participantes da atividade conjunta desenvolvam-na dotados de intencionalidade ou como agentes intencionais. 
Percebemos, no entanto, que o grau de intencionalidade - e, por assim dizer, de compreensão do outro como agente intencional - pode variar dentro das cenas de atenção conjunta. Pensemos novamente no contexto do bebê que chora fazendo com que a mãe atribua ao seu choro possíveis intenções. Até mesmo por se tratar de uma interação em que um dos parceiros ainda está em processo de desenvolvimento cognitivo e de aquisição da linguagem, não podemos afirmar que de fato o choro do bebê foi uma forma de mobilizar quaisquer das intenções inferidas pela mãe. Outra situação de atenção conjunta poderia ser identificada em uma loja de brinquedos. Supondo que duas crianças observem na vitrine um mesmo brinquedo, que é peça única, e ainda prestam atenção ao fato de que ambas estão interessadas no produto, poderíamos perceber que houve, neste contexto, uma intenção mais implícita de informar que poderia haver uma disputa por aquela peça. Por fim, um terceiro exemplo seria uma situação em que duas crianças estão jogando bola e, acidentalmente, a bola vai para mais distante de onde elas estão. Uma delas, ainda assim, está mais próxima ao local para onde a bola foi, e a outra alterna o olhar entre a bola e a criança que está mais próxima ao objeto, informando ainda que este foi para o lugar determinado por meio de um gesto de apontar, por exemplo. Nessa situação, se a informação fosse trocada, a criança mais próxima ao local onde a bola está perceberia a proposta presente na cena de atenção conjunta e iria buscá-la, mesmo sem que esta tenha sido explicitamente proferida.

Voltando à discussão conceitual e debruçando-se sobre a noção de intencionalidade compartilhada, Tomasello e Carpenter (2007, p.121) dizem que esta noção "se refere a interações colaborativas em que os participantes compartilham estados psicológicos

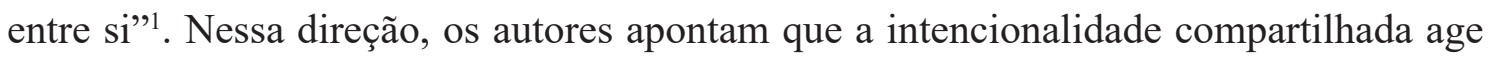
sobre quatro habilidades já adquiridas pelas crianças.

A primeira refere-se à "habilidade de acompanhamento do olhar e atenção conjunta" 2 e diz respeito à capacidade que a criança demonstra de, reconhecendo a existência do outro, perceber seu olhar e compartilhar com ele desse mesmo ponto de atenção. Nessa primeira habilidade, está inserida a transição entre o olhar compartilhado dois sujeitos olhando fixamente para um mesmo elemento externo - e "a atenção conjunta plena"3 (PEACOCKE, 2005, p. 298), em que ambos os participantes compreendem que têm a atenção voltada a um elemento externo em comum.

\footnotetext{
${ }^{1}$ Tradução nossa para "[...] refers to collaborative interactions in which participants share psychological states with one another".

2 Tradução nossa para "gaze following and joint attention" (TOMASELLO \& CARPENTER, 2007, p. 121).

${ }^{3}$ Refere-se à tradução nossa para o conceito de "full joint attention". 
A segunda habilidade, "manipulação social e comunicação cooperativa", é representada pelos gestos utilizados pela criança com a intenção de se comunicar, sendo estes controlados pela motivação e pela intencionalidade compartilhada (MELO, 2015). Ou seja, a criança não utiliza os gestos aleatoriamente, mas sim a partir de sua intenção na troca comunicativa.

A habilidade de "atividade de grupo e colaboração" é a terceira das que são apontadas por Tomasello e Carpenter (2007) e corresponde à capacidade de colaboração entre os parceiros inseridos em uma troca interativa em que ambos têm um mesmo objetivo e executam ações conjuntamente para alcançá-lo. Nessa habilidade, a intencionalidade está presente quando, dentro da atenção conjunta, os sujeitos traçam uma espécie de plano para atingir a meta que compartilham. Traçar um plano, entretanto, não é uma ação literal que poderíamos compreender como a elaboração de uma estratégia, mas sim uma marca do envolvimento dos sujeitos que partilham um determinado objetivo.

As noções de "aprendizagem social e aprendizagem instruída"6 representam a quarta habilidade discutida em Tomasello e Carpenter (2007). Conforme apontam os teóricos, a aprendizagem social possui, paradoxalmente, um caráter individual, visto que as crianças "recolhem informações unilateralmente [...] dos adultos nos quais confiam"” (TOMASELLO; CARPENTER, 2007, p. 123), ou seja, de adultos com os quais as crianças já têm estabilizada uma rotina interativa a ponto de tomá-los como referências sociais (EILAN, 2005). Já a aprendizagem instruída refere-se às situações de interação nas quais os adultos ensinam algo às crianças por meio de demonstração. Ambas as formas de aprendizagem se inserem na intencionalidade compartilhada quando as crianças recorrem à imitação do que foi aprendido não apenas motivadas pelo objetivo de desempenhar a ação, mas também para mostrar ao adulto o que aprenderam.

Nesse sentido, retornamos a Tomasello (2003) quando ele afirma que para o estabelecimento da atenção conjunta as crianças compreendem o outro como agentes intencionais iguais a elas próprias, percebendo que tanto elas quanto as outras pessoas engajam-se na interação conjunta para cumprir aquilo que se caracteriza como suas intenções. Esses agentes intencionais são, por definição, seres animados que "têm

\footnotetext{
${ }^{4}$ Tradução nossa para "social manipulation and cooperative communication" (TOMASELLO \& CARPENTER, 2007, p. 122).

${ }^{5}$ Tradução nossa para "group activity and collaboration" (TOMASELLO \& CARPENTER, 2007, p. 123).

${ }^{6}$ Tradução nossa para "social learning and instructed learning" (TOMASELLO \& CARPENTER, 2007, p. 121).

${ }^{7}$ Tradução nossa para "[...] gather information unilaterally [...] from unsuspecting adults". 
objetivos e fazem escolhas ativas entre meios comportamentais para alcançar tais objetivos"》 (CARPENTER et al., 1998, p. 4).

Acreditamos que os participantes da atenção conjunta - quer seja entre adultos e crianças, entre crianças, ou até mesmo entre adultos apenas - não se engajam neste processo aleatoriamente. Dessa forma, compactuamos, ao final desta seção, com a ideia de que existe, em certo grau - já que a intencionalidade é um processo subjetivo e que, portanto, não se pode medir -, intencionalidade nas ações dos sujeitos que se envolvem na atividade conjunta. Esse posicionamento norteará a análise dos dados que apresentaremos mais adiante.

\section{AMPLIANDO A (DELICADA) QUESTÃO DA INTENCIONALIDADE}

Conforme já destacamos neste artigo, a atenção conjunta, assim como outras estratégias não verbais, tende a garantir, na interação com os sujeitos que as cercam, o lugar de crianças que ainda não dominam a estrutura verbal da língua. Nesse sentido, o adulto que interage com a criança busca nas produções não verbais infantis o significado daquilo que a criança deseja "falar". É evidente que o contexto no qual a interação social - e mais especificamente a cena de atenção conjunta propriamente dita - ocorre, exerce extrema importância para a interpretação do adulto.

Há, então, dois movimentos: o primeiro é o que a criança realiza, isto é, suas ações/produções dentro da interação com o adulto; o segundo, por sua vez, ocorre quando o adulto busca e confere o sentido às ações da criança. Esse movimento nos permite considerar que o adulto pressupõe desde o início da cena interativa de atenção conjunta que as produções não verbais desempenhadas pela criança possuem um significado. Retomando o exemplo anteriormente discutido com o choro da criança, podemos ver que o adulto, ao ouvir o bebê chorando, pressupõe que algo está acontecendo (a criança está com fome, com cólicas, com sono, etc.). Ao mesmo tempo, por meio da estabilização da rotina e das formas de aprendizagem social e instruída (TOMASELLO e CARPENTER, 2007), mencionadas anteriormente, a criança começa a perceber que ao chorar, ela atrai a atenção do adulto. Isso nos permite retomar Carpenter et. al. (1998), quando os autores associam a definição de agente intencional às escolhas feitas pela criança (o agente) para atingir um determinado objetivo.

\footnotetext{
${ }^{8}$ Tradução nossa para "[...] have goals and make active choices among behavioral means for attaining those goals".
} 
Compreendendo a noção de agente intencional e, por meio dela a da própria intencionalidade, podemos perceber que esse conceito inserido no processo de atenção conjunta não se trata, necessariamente, de uma busca por mensurar ou quantificar a intenção da criança quando se engaja em uma cena de atenção conjunta com o adulto, mas sim diz respeito aos recursos mobilizados pela criança para conseguir se engajar na cena de atenção conjunta. Em outras palavras, a intencionalidade na atenção conjunta pode ser percebida como as ações multimodais que a criança realiza para constituir a interação. Essas ações, no entanto, não surgem aleatoriamente, mas sim ao longo dos processos que servem de base à atenção conjunta e à comunicação intencional, isto é, as quatro habilidades mencionadas por Tomasello e Carpenter (2007) já apresentadas na seção anterior.

Sabemos que compreender a intencionalidade na atenção conjunta a partir da perspectiva acima significa ampliar o próprio conceito de intencionalidade. Para isso, deslocamos nosso olhar às concepções de intencionalidade e aceitabilidade propostas por Beaugrande e Dressler (1981) na Linguística Textual.

Em primeiro lugar, para que seja possível esse deslocamento entre campos de investigação da Linguística, precisamos conceber, sob um viés de Bakhtin (2003), que toda atividade humana de interação social ocorre por meio de gêneros discursivos, que se referem a formas nas quais os textos produzidos nos mais diversos contextos se materializam. Em segundo lugar, precisamos situar os conceitos de intencionalidade e aceitabilidade para que seja possível alcançar o paralelo conceitual que desejamos propor neste artigo.

Dentre os sete fatores de textualidade apontados por Beaugrande e Dressler (1981) como características que permitem ao texto ser concebido como tal e não apenas como um amontoado de frases, a intencionalidade e aceitabilidade referem-se a aspectos contextuais observados no texto. A primeira noção, a de intencionalidade, refere-se às ações do produtor para que sua produção seja coesa e coerente e, desse modo, alcance um sentido. Ações estas que, na interação de atenção conjunta, mostram-se por meio das produções verbais e não verbais da criança no momento da interação, dada por meio e sob o formato de um determinado gênero discursivo.

Como os conceitos de intencionalidade e aceitabilidade são interligados na teoria proposta por Beaugrande e Dressler (1981), e é deste lugar que tentamos contribuir para a compreensão da intencionalidade na atenção conjunta, precisamos também relacionar o segundo conceito, o de aceitabilidade, ao processo interativo que estudamos. A aceitabilidade como fator textual é compreendida como as atitudes que o ouvinte 
(interlocutor) tem no sentido de pressupor que o texto que lhe foi dado possui um sentido e buscar conferir sentido à produção. Assim, retomando mais uma vez o exemplo em que a criança chora para chamar a atenção da mãe, o que poderíamos chamar de aceitabilidade dentro do processo de atenção conjunta se ancora na ação do adulto, que busca compreender o motivo pelo qual a criança desempenhou tal comportamento, isto é, a mãe interpreta o choro da criança como fome, ou sono, ou cólicas, etc.

Após percebermos os conceitos de intencionalidade e aceitabilidade com o auxílio da teoria da Linguística Textual, situando-os no contexto interativo da atenção conjunta, apresentaremos a seguir dois recortes que se referem ao processo de interação destacado. Considerando o caráter inicial da proposta de compreensão do conceito de intencionalidade trazida no presente artigo, que eventualmente poderá servir como ponto de partida para estudos mais aprofundados sobre o tema por meio de um corpus, destacamos que nosso intuito está restrito a exemplificar nossa discussão por meio dos recortes extraídos de diferentes contextos e pesquisas sobre atenção conjunta com crianças. Por serem, dessa forma, distintos os contextos nos quais estão situadas as cenas que serão descritas, buscaremos expor brevemente como cada dado foi coletado.

\section{EXEMPLIFICANDO}

O primeiro contexto de atenção conjunta que utilizaremos faz parte de um arquivo pessoal de uma mãe ${ }^{9}$ com seus dois filhos. A cena, nomenclatura utilizada por Tomasello (2003) e que usaremos para cada um dos exemplos, não foi registrada em vídeo, mas sim na forma de um diário em que foi descrito o contexto da cena e as produções dos participantes.

\section{Cena 1}

Participantes:

P1 - Mãe

P2 - Adulto, amigo da mãe

C1 - Filha mais velha (2 anos)

C2 - Bebê (2 meses)

Contexto: P1 e P2 conversam na sala de jantar, sentados à mesa enquanto lancham. $\mathrm{C} 1$ está brincando próxima à mãe $(\mathrm{P} 1)$, que está com $\mathrm{C} 2$ no colo.

\footnotetext{
${ }^{9}$ A mãe em questão é Doutora em Linguística e desenvolve pesquisas em Aquisição da Linguagem. A utilização dos dados foi autorizada pela mãe/pesquisadora.
} 
C1: Titio, segura neném? (Olha para P2 e depois para C2, estando em pé ao lado de P1).

P1 e P2: (Entreolham-se, sorriem e olham para C1).

P2: Me dá ele. (Olha para P1 e estende os braços para pegar C2 no colo).

P1: (Entrega C2 para P2).

C1: (Senta no colo de P1).

Na cena 1 descrita, temos uma interação de atenção conjunta entre uma criança (C1) e dois adultos (P1 e P2), em que uma outra criança, ainda bebê, (C2), é o foco da interação (objeto foco na teoria de atenção conjunta). Percebemos já no início da cena que $\mathrm{C} 1$ sugere que P2 pegue o bebê (C2) no colo. A sugestão ocorre por meio de uma pergunta e pode gerar pelo menos duas interpretações. A primeira seria a mais óbvia se $\mathrm{C} 1$ não olhasse para $\mathrm{C} 2$, o que poderia indicar que o objetivo de $\mathrm{C} 1$ era ser posta no colo por P2. No entanto, quando C1 intercala o olhar entre P2 (seu interlocutor) e C2 (o foco da cena), o que constitui a atenção conjunta em seu formato clássico, percebemos a possibilidade de uma segunda interpretação, a de que o neném mencionado por $\mathrm{C} 1$ é, na verdade, seu irmão, de modo que o desejo exposto implicitamente pela pergunta seria o de que $\mathrm{P} 2$ pegasse $\mathrm{C} 2$ no colo.

A produção multimodal de $\mathrm{C} 1$ (fala e direcionamento de olhar) representa a ação que ela move na cena de atenção conjunta para atingir um determinado objetivo, o de chamar a atenção de $\mathrm{P} 2$ para que ele pegue o bebê $(\mathrm{C} 2)$ do colo da mãe (P1). Observando o desenrolar da cena, especialmente o final, quando $\mathrm{C} 1$ se senta no colo da mãe, notamos que a escolha desta criança ao produzir seu enunciado multimodal ocorreu de modo a informar aos participantes adultos o desejo de que queria ir para o colo da mãe.

Pensando a partir do lugar dos adultos (P1 e P2), vemos que quando se entreolham e sorriem, eles desempenham uma atitude em relação ao que foi produzido por $\mathrm{C} 1$ buscando conferir um sentido implícito na pergunta da criança.

Por meio da cena, percebemos que de um lado a criança (C1) faz "escolhas" com o intuito de atingir um objetivo, o que remete à intencionalidade, na concepção de Beaugrande e Dressler (1981) presente na interação; de outro, temos os adultos (P1 e P2) compartilhando um sentido que atribuíram à produção de $\mathrm{C} 1$ por meio do contexto $(\mathrm{C} 1$ ao lado da mãe - P1), o que enfatiza ao mesmo tempo o engajamento dos sujeitos na cena de atenção e a atribuição de um sentido coerente ao que $\mathrm{C} 1$ produziu, caracterizando a aceitabilidade, conforme descrito por Beaugrande e Dressler (1981). 
A seguir, traremos a Cena 2, que integra os corpora do Laboratório de Aquisição da Fala e da Escrita (LAFE) ${ }^{10}$, da Universidade Federal da Paraíba. O dado que segue foi coletado conforme regulamenta o Comitê de Ética em um contexto o mais naturalístico possível, isto é, na casa da díade mãe e criança, durante situações rotineiras de interação entre os participantes da pesquisa. Ao contrário da Cena 1, a Cena 2 que segue foi gravada em vídeo e transcrita por pesquisadores do laboratório citado.

\section{Cena 2}

Participantes:

P1 - Mãe

C1 - Criança (1 ano, 3 meses, 23 dias)

Contexto: Mãe e criança estão brincando no quarto do bebê

C1: (Pega um sapato no guarda-roupa).

P1: Ah, o sapato é, né? Pra quê? Pra ir pra rua é? (Olha para C1).

C1: Á! (Estende o sapato para P1, em seguida, retira o outro sapato do guarda-roupa, depois se senta no chão e tenta calçá-lo).

P1: Mas tem que calçar o sapatinho.

C1: Dá! (Levanta-se do chão e estende o sapato para a mãe).

P1: Então me dê o pé pra gente calçar.

Como percebemos na cena 2 descrita anteriormente, o recorte inicia com a criança trazendo para a cena o objeto que se torna foco da interação de atenção conjunta, o sapato. O objetivo inicial parece ser destacar o objeto, já que em sua primeira produção C1 não fornece elementos que possam ser considerados como diretivos. Pegar o objeto é a ação da criança que constitui a intencionalidade dela na cena.

Do ponto de vista da mãe $(\mathrm{P} 1)$, vemos que apenas o fato de a criança $(\mathrm{C} 1)$ ter destacado o objeto foi suficiente para a mãe dar continuidade à interação destacando uma situação em que se usa sapato. Nesse sentido, a mãe age de modo a conferir um sentido ao gesto da criança, dando continuidade à interação e garantindo a aceitabilidade (BEAUGRANDE \& DRESSLER, 1981). Por outro lado, também na fala da mãe (P1) é possível notar intencionalidade, já que ao destacar a função do sapato, ela não apenas atribui um sentido à ação da criança $(\mathrm{C} 1)$, mas também se move para que a criança continue envolvida na cena interativa. O que mostra, inclusive, o caráter contínuo e interativo da atenção conjunta enquanto troca entre sujeitos (COSTA FILHO, 2016).

\footnotetext{
${ }^{10}$ O LAFE é coordenado pelas professoras Dra. Marianne Carvalho Bezerra Cavalcante e Dra. Evangelina Maria de Brito Faria, vinculadas ao Programa de Pós-Graduação em Linguística da Universidade Federal da Paraíba.
} 
Já a segunda produção de C1 mostra uma pequena vocalização acompanhada do gesto de entregar o sapato para P1, pegar o outro sapato e tentar calçá-lo. Como a criança não consegue calçar o sapato sozinha, em um segundo movimento, ela entrega o outro sapato para $\mathrm{P} 1$. Esse movimento de $\mathrm{C} 1$ vai em direção à ação intencional (para que $\mathrm{P} 1$ a ajude), ao mesmo tempo que, quando já segurando o par de sapatos, $\mathrm{P} 1$ pede que a criança estique o pé para calçar o sapato, o que caracteriza a aceitabilidade, já que P1 confere à produção da criança o sentido de um pedido de ajuda para calçar o sapato.

As duas cenas apresentadas são apenas dois exemplos em que podemos observar os movimentos em torno das noções de intencionalidade e aceitabilidade (BEAUGRANDE \& DRESSLER, 1981) trazidas à discussão como forma de ampliar as discussões sobre a atenção conjunta. Ambas, no entanto, fazem-nos refletir sobre a a intencionalidade principalmente quando a criança inicia a interação (como foi o caso das cenas descritas). Inicialmente destacada por Tomasello (1995; 2003), e também discutida em trabalhos como o de Bosa (2002), Melo (2015), Costa Filho (2016) e Ávila-Nóbrega (2017), a noção de intencionalidade parece mais clara dentro do contexto de atenção conjunta, já que ao destacar um objeto foco e convocar o interlocutor adulto à interação, a criança demonstra agir em torno de um objetivo, e não de forma aleatória e desordenada.

\section{ALGUMAS CONSIDERAÇÕES FINAIS}

Ao longo do presente trabalho buscamos discutir a noção de intencionalidade na atenção conjunta. Por considerá-la delicada tanto do ponto de vista conceitual quanto analítico quando se pensa em dados de produções infantis, buscamos relacionar as contribuições dos estudos em Aquisição da Linguagem sobre o tema ao conceito utilizado pela Linguística Textual, como forma de ampliar a compreensão do fenômeno nos contextos de atenção conjunta.

Após discutirmos o termo do ponto de vista teórico, nos dois campos de investigação, trouxemos dois dados de atenção conjunta entre crianças e adultos com o objetivo de ilustrar a relação proposta no artigo. Embora não sejam robustos numericamente, os dados trazidos já nos mostram que analisar a intencionalidade da criança não significa medir sua intenção dentro da cena, mas sim verificar quais escolhas e de que modo ela se move dentro da interação de atenção conjunta em direção a um possível objetivo. Isso porque os sujeitos envolvidos em uma cena interativa, adultos ou crianças, não desempenham ações aleatórias, isto é, em algum grau, eles têm e demonstram, implícita ou explicitamente, objetivos para fazer o que fazem. 
Vimos ainda que a ação intencional parece estar mais marcada na Cena 1, em que a criança, já com dois anos, demonstra mais conhecimento sobre a estrutura da atenção conjunta e da própria comunicação intencional. Isso permite que ela coordene com mais facilidade a interação conjunta, já que a mãe, diferentemente do que acontece na Cena 2, não precisa lançar mão de construções verbais para enfatizar o possível sentido produzido na cena.

Por fim, destacamos mais uma vez a complexidade da temática abordada neste artigo, que gera, inclusive, em pesquisas que abordam a atenção conjunta, dificuldades e contrapontos teóricos. Desse modo, é preciso que enfatizemos que neste artigo não tivemos como objetivo encerrar uma discussão sobre a intencionalidade na atenção conjunta, mas sim ampliar o olhar sobre a temática, permitindo, pois, uma nova perspectiva para que dados desta natureza sejam analisados. Esperamos que a discussão seja aprofundada em futuras pesquisas sobre o tema para que, enfim, possamos dentro da Aquisição da Linguagem obter contribuições cada vez mais fundamentadas sobre a delicada noção de intencionalidade na teoria da atenção conjunta.

\section{REFERÊNCIAS}

ÁVILA-NÓBREGA, P. V. O sistema de referenciação multimodal de crianças com síndrome de down em engajamento conjunto. 2017. 206 p. Tese (Doutorado em Linguística). Universidade Federal da Paraíba, João Pessoa, 2017.

BAKHTIN, M. Estética da criação verbal. 4 ed. São Paulo: Martins Fontes, 2003. Tradução do russo de Paulo Bezerra.

BEAUGRANDE, R. de; DRESSLER, W. Introduction to text linguistics. vol.1. London: Longman, 1981.

BOSA, C. Atenção compartilhada e identificação precoce do Autismo. Psicologia: Reflexão e Crítca. v. 15, n. 1, p 77-88, 2002.

BRUNER, J. Childs Talk: Learning to use language. New York: Norton, 1983.

BRUNER. From communication to language: a psychological perspective. Cognition. v. 3, n. 3, p. 255-287, 1975. 
CARPENTER, M. et. al. Social cognition, joint attention and communicative competence from 9 to 15 months of age. In: Monographs of the society for research in child development. 1998

CAVALCANTE, M. C. B. O gesto de apontar como processo de co-construção na interação mãe-criança. 1994.90 p. Dissertação (Mestrado em Linguística). Universidade Federal de Pernambuco. Recife, 1994.

COSTA FILHO, J. M. S. da. "Olá, Pocoyo!": A constituição da atenção conjunta infantil com o desenho animado. 2011. 139 p. Dissertação (Mestrado em Linguística) Universidade Federal da Paraíba, João Pessoa, 2011.

COSTA FILHO, J. M. S. da. Atenção conjunta: o jogo da referência na realidade virtual. 2016. 215p. Tese (Doutorado em Linguística) - Universidade Federal da Paraíba, João Pessoa, 2016.

COSTA FILHO, J. M. S. da. A referência linguística na atenção conjunta. Entrepalavras, Fortaleza, v. 7, p. 188-205, 2017.

COSTA FILHO, J. M. S. da; CAVAlCANTE, M. C. B. Atenção conjunta virtual e a construção da ação colaborativa. Letrônica. v. 10, n. 2, 513-525, 2018.

EILAN, N. Joint attention, communication and mind. In: EILAN, N. et. al. Joint Attention: communication and other minds. Oxford: OUP, 2005. p. $1-33$.

MELO, G. M. L. de. Cenas de atenção conjunta entre professoras e crianças em processo de aquisição da linguagem. 2015. 227 p. Tese (Doutorado em Linguística). Universidade Federal da Paraíba. João Pessoa, 2015.

PEACOCKE, C. Joint attention: its nature, reflexivity and relation to common knowledge. In: EILAN, N. et. al. Joint Attention: communication and other minds. Oxford: Oxford University Press, 2005.

TOMASEllo, M. Origens Culturais da Aquisição do Conhecimento Humano. Tradução de Cláudia Berliner. Martins Fontes: São Paulo, 2003.

TOMASELLO, M. Joint attention as social cognition. In: MOORE, C.; DUNHAM, P. J. (Eds.). Joint attention: Its origin and role in development. Hillsdale, NJ: Lawrence Erlbaum Associates, 1995. 
TOMASELLO, M.; CARPENTER, M. Shared intentionality. Developmental science, v. 10, n. 1, p. 121-125, 2007.

WOOD, D.; BRUNER, J.; ROSS, G. The role of tutoring in problem solving. Journal of Child Psychology and Psychiatry. 1976. Vol. 17. N. 2. p. 89-100.

Recebido em: 30 jul. 2021.

Aceito em: 09 set. 2021. 